\title{
INTOLERÂNCIA RELIGIOSA E A VIOLAÇÃO DE DIREITOS HUMANOS
}

\section{RELIGIOUS INTOLERANCE AND HUMAN RIGHTS VIOLATION}

Resumo: O presente artigo dedicar-se-á a provocar como as populações de religiões de matrizes africanas estão sendo realmente percebidas no Estado Brasil, tendo em vista a crescente onda de violências às quais estão sendo submetidas diariamente, sejam elas difundidas pela mídia e/ou por omissão estatal. O artigo terá o condão de fazer uma provocação em função omissiva, que esclareça, do ponto de vista formal, o que é racismo, intolerância religiosa, racismo religioso e a propriedade relativa ao bem imaterial, partindo da premissa que nem sempre a legislação existente no Brasil é boa ou ruim, no que se refere à proteção da população negra. O conceito dos termos acima será definido para que o presente artigo esclareça a compreensão dos receptadores. $O$ artigo visa, como premissa, provocar a sociedade em sentido lato, com base na interpretação das leis federais, bem como a responsabilidade de todos os atores participantes na promoção dos direitos humanos, na responsabilização e proteção aos seres que possuem a sua fé na religião de matrizes africanas.

Palavras-chave: Racismo. Intolerância religiosa. Racismo religioso. Bem imaterial.

Abstract: The present article will focus on provoking how the populations of religions of African matrices are actually being perceived in the State of Brazil, given the growing wave of violence to which they are

\footnotetext{
i Possui graduação em Direito pela Faculdade Brasileira de Ciências Jurídicas (2012). Atualmente cursando MBA on line. Tem experiência na área de Direito, com ênfase em Direito. Pessoa com deficiência paralisia cerebral atáxica- atetótica CID 80.4. Finalizando: Pós Graduação pela UFF em fase de entrega de monografia.
} 
being subjected daily, whether it is disseminated by the media and / or by state default. The article will have the power to make a provocation in an omissive function, which will formally clarify what is racism, religious intolerance, religious racism and property related to intangible good, starting from the premise that Brazil is good or bad, as far as the protection of the black population is concerned. The concept of the above terms will be defined so that the present article clarifies the understanding of the receivers. The article aims at provoking society in a broad sense, based on the interpretation of Federal Laws, as well as the responsibility of all actors involved in the promotion of human rights, in the accountability and protection of beings who have their faith in the religion of matrices african countries.

Keywords: Racism. Religious intolerance. Religious racism. Very immaterial.

\section{INTRODUÇÃO}

O presente artigo, de natureza provocativa, possui como objetivo primordial desenvolver os conceitos pertinentes à proteção das pessoas praticantes de religiões de matrizes africanas. Esta proteção é necessária em virtude do avanço das religiões neopentecostais na vida política do País.

Aproximaremos os conceitos de direitos humanos fundamentais, pois estes são decorrentes para o exercício de uma vida plena, que tem proteção constitucional no princípio da dignidade humana.

Neste contexto pode-se afirmar que o objetivo principal é provocar os atores políticos para que estes interpretem o caráter de compromisso da Constituição da República Federativa do Brasil, afirmada logo em seu preâmbulo.

O documento irá abordar diferentes conceitos encontrados em doutrinas, legislações, artigos e também no conhecimento empírico, uma vez que não há dados desagregados das violências sofridas pelos praticantes de religiões de matrizes africanas em órgão oficial, o que, por si só, já referencia a omissão do Estado. Estas violências podem ser contra a propriedade, sendo caracterizados como bem material e bem imaterial a moral, a liberdade de consciência, de crença e de culto religioso e a personalidade, todos direitos fundamentais. 
O estudo parte da premissa que o presente artigo deverá, não apenas se preocupar em servir de base para futuros pesquisadores acadêmicos, mas também para a sociedade, pois o objetivo central é discutir, instigar e responsabilizar o Estado a partir de sua responsabilidade.

\section{DESENVOLVIMENTO}

Neste diapasão, a Carta Magna possui como diretriz a ser alcançada a proteção dos direitos fundamentais, que objetiva alcançar uma igualdade material, por força da Constituição da República Federativa do Brasil. Neste contexto a responsabilidade pertence, de forma principal, aos seguintes atores: Executivo, Legislativo e Judiciário - que possuem obrigações, com base no poder-dever na proteção dos direitos humanos fundamentais individuais e coletivos de uma sociedade. Neste tocante e especialmente em virtude de sua vulnerabilidade é que as religiões de matrizes africanas necessitam de um tratamento diferenciado em virtude de todo o contexto histórico/repressor e que no decorrer de toda a humanidade sempre foram tratadas de forma pejorativa, principalmente na pessoa preta.

Os tratamentos pejorativos são decorrentes de preconceitos sofridos praticados pela cultura eurocêntrica europeia, que, desde o inicio da colonização do País, fez-se presente e, em função de sua hegemonia, impôs a este povo, que foi sequestrado e escravizado, a sua crença e cultura baseada no eurocentrismo europeu.

Mesmo com a evolução temporal, não há que se falar que existe igualdade substancial, em virtude de inexistência de políticas públicas eficazes que visem a reparar, atenuar e proteger os seres humanos, ou seja, as pessoas praticantes das religiões de matrizes africanas.

O estudo parte da premissa que o presente artigo deverá, não apenas se preocupar em servir de base para futuros pesquisadores acadêmicos, mas também para a sociedade, pois o objetivo central é discutir, instigar e responsabilizar a omissão de Estado que, dependendo do ponto de vista do receptor, pode ser caracterizada como comissiva ou omissiva. Esta provocação é necessária em função de eventual culpa do Estado. Embora a Carta Magna adote como regra a teoria objetiva na modalidade risco administrativo, também há que ser destacado que o particular possui a sua responsabilidade por danos praticados contra o seu par. 
Esta discussão possui como núcleo provocar todos os atores participantes da vida em sociedade: dos três atores governamentais e também os atores não governamentais, entretanto os três poderes governamentais possuem o direito/dever de nortear os demais, assumindo a sua responsabilização.

Neste contexto há duas vertentes: a responsabilidade omissiva ou comissiva, que se caracteriza pelo deixar de fazer ou fazer pelos atores governamentais, e o particular que possui a responsabilidade objetiva. Do ponto de vista estatal, esta responsabilidade pode ser comissiva, quando o Estado escolhe deixar de fazer ao não criar políticas públicas eficazes de proteção e promoção das religiões de matrizes africanas por ausência de interesse de agir do Poder Legislativo. Esta ausência é legislativa e, apesar de crescente, em virtude de uma presença cada vez maior das religiões pentecostais no órgão, a cultura eurocêntrica continua dominante.

Sob o ponto de vista omissivo, podemos provocar que simplesmente não há interesse porque as religiões de matrizes africanas, a partir de dado empírico, são praticadas em sua grande maioria pela população preta, e a sua proteção iria de oposição ao racismo estrutural existente em toda a sociedade, sem distinção entre atores governamentais e não governamentais.

Desta forma, o elemento central que dará inicio ao presente artigo é a norma positivada no ordenamento jurídico brasileiro, desconsiderando, no momento, a existência de documentos internacionais anteriores à Carta Magna que será devidamente analisada em momento oportuno.

Assim, o trabalho possui como elemento central a Constituição da República Federativa do Brasil de 1988, cujo objetivo, quando formulado, foi de implantar a dignidade humana, a igualdade, a propriedade e o estado social, dentre outros direitos fundamentais e, simultaneamente, servir de parâmetro de compromisso perante a totalidade da população existente sob a jurisdição do Estado Brasil, podendo ser facilmente compreendido com a leitura do Preâmbulo Constitucional que porta o caráter de compromisso perante todos aqui tutelados pelo Estado, independentemente de sua religião, pois, "em principio", o Estado seria laico, sendo assegurado o livre exercício de cultos religiosos, tal como segue abaixo o Preâmbulo de CRFB/88.

"Nós, representantes do povo brasileiro, reunidos em Assembleia Nacional Constituinte para instituir um Estado Democrático, destinado a assegurar o exercício dos direi- 
tos sociais e individuais, a liberdade, a segurança, o bem -estar, o desenvolvimento, a igualdade e a justiça como valores supremos de uma sociedade fraterna, pluralista e sem preconceitos, fundada na harmonia social e comprometida, na ordem interna e internacional, com a solução pacífica das controvérsias, promulgamos, sob a proteção de Deus, a seguinte..." CONSTITUIÇÃO DA REPÚBLICA FEDERATIVA DO BRASIL, 1988, (BRASIL, 1988).

Percebe-se, com a promulgação da Constituição Federal, que o País se compromete, tanto na ordem interna quanto na internacional, a proteger diversos direitos, dentre os quais podemos destacar o direito fundamental de liberdade de crença e o direito de propriedade, tendo, inclusive, um capitulo exemplificativo que afirma que estes são direitos fundamentais, todos existentes a partir do fundamento do princípio da dignidade humana, o qual será debatido a partir de interações com as diversas normas existentes e atores envolvidos no processo, que no presente trabalho, abordará somente a responsabilização estatal.

Dentre esses direitos, entende-se que as religiões de matrizes africanas também são um direito fundamental e, para tanto, possuem garantias: constitucionais, infraconstitucionais e internacionais - o próprio documento nacional conferiu à religião este status quo, com a positivação da seguinte norma constante no artigo $5^{\circ}$ do mesmo diploma legal, inclusive no que se refere à cultura deste povo.

"Art. $5^{\circ}$ Todos são iguais perante a lei, sem distinção de qualquer natureza, garantindo-se aos brasileiros e aos estrangeiros residentes no País a inviolabilidade do direito à vida, à liberdade, à igualdade, à segurança e à propriedade, nos termos seguintes:

VI - é inviolável a liberdade de consciência e de crença, sendo assegurado o livre exercício dos cultos religiosos e garantida, na forma da lei, a proteção aos locais de culto e a suas liturgias;

V- é assegurado o direito de resposta, proporcional ao agravo, além de indenização por dano material, moral ao à imagem;

X - são invioláveis a intimidade, a vida privada, a honra, a imagem das pessoas, assegurado o direito à indenização pelo dano material ou moral decorrente de sua violação (BRASIL, 1988)." 
Por se tratar de direitos fundamentais, pode-se afirmar que os mesmos possuem como características os seguintes elementos: historicidade, aplicação horizontal, indivisibilidade, relatividade, universalidade, inalienabilidade, imprescritibilidade e são irrenunciáveis, principalmente a aplicação de imprescritibilidade, que se opõe à cultura hegemônica eurocêntrica perpetuada na humanidade. Assim como a violência contra as religiões africanas possui o viés racista historicamente permitido pelo grupo detentor da hegemonia social, nesse contraponto a nossa Carta Magna afirma que o racismo é inafiançável, imprescritível e sujeito a reclusão, de acordo com o inciso XLII do artigo $5^{\circ}$ da CRFB/88. Entretanto, este direito ainda é uma utopia, em virtude da omissão estatal e, consequentemente, da sua responsabilização por danos suportados pelos praticantes de religião de matrizes africanas.

Outrossim, a própria Constituição Federal do Brasil de 1988 reconhece, a contrario sensu, que o País possui como característica ser desigual. Tanto é verdade que o Estado tem como objetivo "promover o bem de todos sem preconceitos de origem, raça, cor, sexo, idade e quaisquer outras formas de discriminação", e assim conclui que as religiões de matrizes africanas possuem direitos a menos, sendo necessário políticas de ações afirmativas, pois a violação dos direitos humanos é intergeracional em função principalmente da questão racial que permanece nos dias atuais, embora com uma denominação que nos passa uma sensação de igualdade.

É bem verdade que na documentação constituinte originária o Estado se comprometeu a promover o bem-estar social de todos e, dentro deste bem-estar, é dever dos órgãos públicos promover e proteger as religiões de forma igualitária, tendo em vista que o País é laico e todos têm o direito fundamental à religião protegida constitucionalmente.

Assim, pode-se observar atualmente a responsabilidade estatal, pois as religiões aqui no Brasil não possuem um tratamento isonômico por parte do Estado e têm como uma das causas que contribuem para esta forma desigual de tratamento, o crescimento da "Nova Direita Cristã" (QUINTÃO, 2017, p. 53), que possui como um dos marcos o ano de 1986, pois houve a atuação dos evangélicos na esfera política do Brasil transformado, com a sua visão hegemônica eurocêntrica, e "também há uma irrupção pentecostal que rompe com o dito tradicional de que crente não se mete em política" (FRESTON, 1993; PIERUCCI, 1989). 
Este caráter de hegemonia religiosa sempre negou a importância do papel das pessoas escravizadas na formação do Brasil, e as religiões africanas tiveram um papel também de construção social e que até os dias de hoje não está sendo reconhecida a sua importância, tanto na construção material do País, quanto em outras religiões, ou seja, com a sua construção imaterial de religiosidade.

É nítido que os negros foram escravizados e sequestrados de sua terra natal para o Estado hoje denominado Brasil, e uma das formas de manterem a sua cultura foi justamente preservar a sua religiosidade, não aceita pelos escravocratas hegemônicos e que, fazendo um paralelo com os dias de hoje, passado e presente se reencontram, pois a religião africana ainda é discriminada pelo Estado e pela sociedade.

Assim é que esta população continua com a sua fé e a prática da religião de matrizes africanas é e sempre foi de resistência, o que incomoda o poder eurocêntrico, que ainda hoje domina o Brasil. Desta forma pode-se afirmar que o princípio da igualdade nunca foi implementado de forma eficaz, não passando de um principio formalmente descrito na Constituição, mas que não possui eficácia, tendo em vista a sua inaplicabilidade pelos atores governamentais e assim se caracteriza a responsabilidade do Estado.

Pode-se perceber que o racismo é uma estrutura, um marco no Brasil que, desde o dito "descobrimento do Brasil", a população negra é maioria no País, porém o poder eurocêntrico sempre com a sua cultura de dominação até os dias atuais, considera-se uma raça superior, inclusive na questão religiosa.

Assim, o racismo possui inúmeras nomenclaturas no que diz respeito às religiões africanas - racismo, racismo religioso, intolerância religiosa -, estas já conceituadas por legislação e doutrinadores, mas este artigo se permite cogitar por que não poderia ser considerado racismo religioso imaterial, pois também possui uma clara violação à propriedade, seja ele material ou imaterial, porque a fé é um bem.

Primeiramente, devemos analisar que a religião somente é praticada por pessoas e possui várias formas e denominações. Desta forma, enquanto seres humanos, estes possuem uma dignidade que deve ser protegida - a "dignidade da pessoa humana" - que é um princípio fundamental em nosso ordenamento jurídico (BRASIL, 1988). 
Corroborando com a importância do principio acima, segue abaixo o conceito de dignidade humana:

\begin{abstract}
"A dignidade é um valor espiritual e moral inerente 'à pessoa, que se manifesta singularmente na autodeterminação consciente e responsável da própria vida e que traz consigo a pretensão ao respeito por parte das demais pessoas, construindo-se um mínimo invulnerável que todo estatuto jurídico deve assegurar, de modo que, somente excepcionalmente, possam ser feitas limitações ao exercício de direitos fundamentais, mas sempre sem menosprezar a necessária estima que merecem todas as pessoas enquanto seres humanos' (MORAES, 2003, p. 50)."
\end{abstract}

O que se percebe é que, a partir do significado do que é racismo, este possui como característica, separar as pessoas, o que, por si só, é uma violação a todos os direitos fundamentais do homem propostos na Constituição Federal.

\footnotetext{
"A partir daí, o racismo pode ser visto também como um sistema, dada sua ampla e complexa atuação, seu modo de organização e desenvolvimento através de estruturas, políticas, práticas e normas capazes de definir oportunidades e valores para pessoas e populações a partir de sua aparência, atuando em diferentes níveis (JONES, 2002 apud WERNECK, 2016, p. 541)."
}

A Constituição Federal abomina toda e qualquer discriminação, seja ela religiosa ou racial. No presente artigo é demonstrada a violação de ambas as segregações. A Carta Magna tem como objetivo promover a todas as pessoas um tratamento igualitário, porém esta igualdade ainda se encontra em plano abstrato, carecendo de posição governamental, através de seus atores governamentais no combate à temática trazida no presente artigo.

Com o avanço das religiões no sistema político, torna-se mais nítido o comportamento dos representantes da religião eurocêntrica nas formulações de questões políticas e pautas, conforme suas diretrizes, desconstituindo, assim, o caráter laico do Estado, o princípio da igualdade, da liberdade e da crença.

Entende-se que as religiões de matrizes africanas, além de serem um momento de fé, são também uma forma de resistência que se per- 
petuou no decorrer do tempo e que se caracteriza na sua prática como autonomia de expressão de liberdade e pensamento, o que vem a ser também uma garantia constitucional, assim como o direito à propriedade.

A violação da religiosidade, quando imposta pela cultura do eurocentrismo, é um constrangimento à pessoa humana de forma a renunciar a sua fé, e representa o desrespeito à diversidade democrática de ideias, à filosofia e à própria diversidade espiritual (MORAES, 2003, p. 73).

Neste diapasão, entende-se como forma de complementar o conceito de dignidade humana, os direitos e garantias fundamentais e os seguintes elementos: os direitos do homem, os direitos humanos e os direitos fundamentais.

Entende-se como direitos do homem aqueles que são adquiridos com o nascimento, pois este é um ser humano, e, como tal, deve ser protegido, independentemente de quaisquer documentos escritos.

Os direitos humanos também partem da premissa de proteção do ser humano de forma mais abrangente e escrita, alcançando toda a população mundial, não havendo fronteiras no que tange à proteção dos direitos e garantias fundamentais.

Em consonância com os dois entendimentos acima, há um terceiro elemento, que abrange a esfera de determinado país e que, no caso do Brasil, são os direitos fundamentais que se encontram positivados em todo o ordenamento jurídico interno, possuindo como norma central a Constituição Federal.

Neste diploma legal, além de todos os direitos e garantias fundamentais, destaca-se, por ser objeto do artigo, o direito de liberdade, de propriedade, de crença e combate ao racismo, que em seu artigo $5^{\circ}$, inciso XLII, afirma que a prática de racismo constitui crime inafiançável e imprescritível, sujeito à pena de reclusão, nos termos da Lei (BRASIL, 1988).

Neste contexto, o racismo "é uma teoria antropológica ou política baseada neste sentimento, que sustém a superioridade de certas raças sobre outras e que, em ocasiões, há perseguições a um grupo étnico, considerado inferior: 'segregação'"' (Dicionário Enciclopédico llustrado, 2009, p. 744).

Diante deste modelo de divisão provocado por senso de superioridade baseado na cor das pessoas é que atualmente as religiões africanas estão sofrendo todo o tipo de represália, seja física, moral ou psicológica, de forma individualizada ou coletiva, por ausência de políticas públicas que são um dever de Estado. 
Neste contexto de violência, as religiões de matrizes africanas entendem-se como subjugações da religiosidade, entretanto, deve-se analisar que a introdução desta cultura no Brasil partiu do sequestro da população negra do continente africano para ser escravizada aqui neste país e que, por possuir características de resistência é que as pessoas escravizadas negaram a religiosidade hegemônica que aqui predominava e ainda predomina.

Com esta emancipação forçada de sua região, a religião africana tornou-se um movimento de resistência à cultura europeia, ou seja, a religiosidade possui como característica principal a resistência de sua cultura frente aos colonizadores.

Uma das formas de manutenção de sua identidade foi a oralidade, pois os escravizados não possuíam permissão para se comunicarem entre si; desta forma este meio de comunicação foi primordial para manterem a cultura religiosa com seus irmãos, e assim permanece atualmente, mas seguem sendo amplamente violados os seus direitos, como no passado.

É de conhecimento não acadêmico e não desagregado, em virtude da omissão estatal, que as religiões africanas são praticadas em sua maioria pela população negra em análise empírica, tendo em vista que a maioria da população no Brasil é negra e a religião surgiu no continente africano e esta ausência de dados oficiais é uma omissão do Estado.

Assim, a religião de matriz africana deve ser considerada hoje uma religião contra-hegemônica, podendo extrair que a omissão de informação também é um dos indicadores que as pessoas e as religiões não são respeitadas, pois não há dados desagregados, o que seria um dos elementos para a criação de políticas públicas.

Diante desta falta de interesse pelos atores governamentais, que seriam os responsáveis por estes dados desagregados, indaga-se: é racismo devido a sua prática ser pela população negra ou racismo religioso, devido à resistência contra a cultura eurocêntrica europeia? E por que não poderia também ter a nomenclatura de racismo religioso imaterial, pois além dos elementos acima, também há uma violação ao direito de propriedade.

É certo que o núcleo da violação dos direitos fundamentais é questão racial, ou seja, o fato gerador é a raça, tanto na esfera civil quanto na esfera penal, mas é necessário avaliar que a violação supera a questão racial, alcançando a religião e a propriedade.

O presente artigo já apresentou o significado de racismo e neste 
momento será abordada a liberdade de crença e cultos religiosos que, pela Constituição Federal, também é um direito fundamental e, para tanto, goza de garantias e proteção estatal.

Entretanto, esta liberdade de crença não está materializada e sim marginalizada quando não há uma resposta efetiva do Estado no combate à violação do direito do ser humano de poder escolher a sua própria religião, sem que este sofra com a sua escolha.

Assim, o artigo tem natureza de provocar o receptador, para que este analise a responsabilidade do Estado.

Porém, do ponto de vista do autor, a responsabilidade estatal é omissiva, porém, mesmo sendo comissiva, não excluiria a responsabilidade do Estado pela violação que as pessoas praticantes e adeptas da religião supracitada sofrem com a violência imposta pelo Estado e pela sociedade.

De antemão não é intolerância religiosa, é racismo mesmo, é dominação. Quem pratica esses crimes sabe que candomblé é resistência, muito mais que questão de religião; e de onde você resgata uma identidade que foi retirada, é onde você consegue afirmar sua identidade (PARA LÍDERES..., 2016).

E o nome "intolerância religiosa" não consegue descrever o que acontece com esses povos. Há várias outras religiões que não são cristãs e não são atacadas da forma como vem ocorrendo (NASCIMENTO, 2016).

Quando o Estado se omite na proteção aos grupos vulneráveis, o mesmo também é responsável pelo crime de racismo e, consequentemente, entende-se que o Estado possa vir a ser compelido a reparar os danos, em todas as suas formas, por não proteger os direitos fundamentais, reconhecendo e reparando o bem material e imaterial.

A responsabilidade estatal está prevista no próprio Texto Constitucional que imputa ao Estado a responsabilidade da teoria objetiva, na modalidade risco administrativo. É bem verdade que não há possibilidade de prisão para o órgão ou seus entes, porém, o agente investido de poder estatal é passível de cometer crime, seja ele por omissão ou ação.

A responsabilidade objetiva é uma garantia do cidadão, não do Estado; e não havendo correlação com quem deve ou deveria realizar a prestação, a responsabilidade objetiva encontra amparo legal na seguinte norma constitucional:

"Art. 37. A administração pública direta e indireta de qualquer dos Poderes da União, dos Estados, do Distrito Fede- 
ral e dos Municípios obedecerá aos princípios de legalidade, impessoalidade, moralidade, publicidade e eficiência e, também, ao seguinte:

$\S 6^{\circ}$ As pessoas jurídicas de direito público e as de direito privado prestadoras de serviços públicos responderão pelos danos que seus agentes, nessa qualidade, causarem a terceiros, assegurado o direito de regresso contra o responsável nos casos de dolo ou culpa (BRASIL, 1988)."

Entende-se que, embora o agente público atue dentro de seu estrito cumprimento de dever legal e não seria responsável por danos causados a terceiros, este agente está autorizado pela Constituição Federal a aplicar e estender a norma na proteção dos direitos e garantias fundamentais, sem que nisso haja violação na separação dos poderes, ou seja, o agente é responsável pela proteção ao crime de racismo. Embora o Poder Legislativo não tenha admitido de forma clara e objetiva, o Poder Judiciário possui a permissão legal de interpretação da Constituição, assim como das demais normas.

Assim, quando o Poder Legislativo tipifica no Código Penal a prática de racismo como injúria ou intolerância, esta norma não comporta, em princípio, a interpretação extensiva do julgador, limitando, assim, a atuação do Poder Judiciário.

Assim, não existe em primeiro momento o racismo decorrente da religião, portanto, toda a violação contra as religiões africanas está sendo tipificada como injúria racial ou intolerância religiosa, quando na verdade o elemento de tipo é a violação da raça negra. Diante de tal situação, o que se percebe é a omissão do Estado na figura do Legislativo em proteger a população negra, resistente e sequestrada com base na crescente onda cristã.

Com a tipificação de racismo, seja como injúria ou intolerância religiosa, este perde o caráter de imprescritibilidade e de crime de maior potencial ofensivo e passa a ser um crime prescritível e de menor potencial ofensivo, conforme artigos 140 e 208 do Código Penal que dizem:

\footnotetext{
"Artigo 140. Injuriar alguém, ofendendo-Ihe a dignidade ou o decoro:

$\S 3^{\circ}$ Se a injúria consiste na utilização de elementos referentes a raça, cor, etnia, religião, origem ou a condição de pessoa idosa ou portadora de deficiência: Pena - reclusão de um a três anos e multa (BRASIL, 1940)."
} 
"Artigo 208. Escarnecer de alguém publicamente por motivo de crença ou motivo religioso; impedir ou perturbar cerimônia ou prática de culto religioso; vilipendiar publicamente ato ou objeto de culto religioso. Pena - detenção de um mês a um ano, ou multa (BRASIL, 1940)."

Desta forma, é clara e evidente a omissão legislativa em punir o responsável pelo racismo. Enquanto no Texto Constitucional o bem protegido é a proteção da raça, no Código Penal a única preocupação é com o sentimento religioso. Entretanto, na prática, como dito acima, o racismo e a religião, no que se refere às religiões africanas, são dois binômios: raça e religião, portanto inseparável.

Quando há violação às religiões supracitadas, estas violências não atingem somente a raça e a religião, mas também a propriedade individual ou coletiva aos praticantes de sua religiosidade.

Tal propriedade é denominada de propriedade imaterial, pois a religião é um patrimônio. Entende-se por patrimônio tudo aquilo que se encontra ao nosso redor, podendo ser caracterizado como importante ou não, concreto ou abstrato. Este juízo de valor é individual e, por ser patrimônio da religiosidade, deve ser protegido e normatizado pelo Estado, como violação à propriedade.

A religião ou religiosidade possui como característica proteger uma identidade e também uma propriedade. Desta forma, faz-se necessário uma proteção governamental. Entende-se que se trata de bem (propriedade) imaterial pois há uma relação pessoal com o objeto, sendo um bem abstrato, de visualização ideal e infungível, que é conceituado a contrario sensu do:

"Artigo 85. São fungíveis os móveis que podem substituirse por outros da mesma espécie, qualidade e quantidade (BRASIL, 2002)."

Assim, quanto há violação das religiões de matrizes africanas pode-se concluir que há três elementos suscetíveis pela proteção do Estado: a raça, a religião e a propriedade.

Nota-se ainda uma omissão legislativa para tal proteção e, assim, o Poder Judiciário possui o dever constitucional de intervir nas relações religiosas sem que isto seja considerado uma invasão de poder.

Neste pilar constitucional podemos citar três atores governamentais: o Executivo, o Legislativo e o Judiciário, que, por força normativa "são independentes e harmônicos entre si" (BRASIL, 1988), o que não significa 
dizer que cada um dos Poderes possa atuar isoladamente, pois estão limitados pela Teoria dos Freios e Contrapesos.

Desta forma, quando o Judiciário intervém nos demais Poderes na proteção das pessoas praticantes das religiões de matrizes africanas, seja com a implementação de políticas públicas ou até mesmo com uma nova interpretação legislativa, estará atuando dentro dos poderes que foram constituídos ao Poder Judiciário pela própria Constituição Federal.

Portanto, não há e nem haverá qualquer violação aos Poderes, pois o Judiciário não estará contrário à democracia, embora seus membros não tenham sidos eleitos pelos cidadãos.

A própria Constituição Federal determina ao Poder Judiciário "apreciar lesão ou ameaça a direito" (BRASIL, 1988), no que tange à proteção de direitos e garantias fundamentais.

Devido à ameaça ou lesão às religiões de matrizes africanas, o Poder Judiciário não se limita às funções meramente declarativas de direitos, impondo-se, entre os demais Poderes, como uma agência indutora dos efetivos Checks and Balances e de garantia de autonomia individual e cidadã (WERNECK VIANNA, 1999, p. 24).

Corroborando com a doutrina acima, o responsável por interpretar a Constituição Federal e as demais normas jurídicas é o Judiciário, que é qualificado para tal ato, tendo como características proteger a Lei, através de sua função contramajoritária de jurisdição constitucional por força normativa.

Assim, quando o Judiciário extrai da Constituição os princípios norteadores de tal diploma, este não estaria legislando e sim interpretando a vontade do legislador constituinte e, portanto, agindo democraticamente.

Desta forma, frente à inércia dos demais poderes, quem detém o poder e o dever de atuar é o Judiciário, porém este também está inerte. Só com o combate efetivo à violação à raça, à religião e ao patrimônio é que se atingirá a igualdade material perseguida conforme comprometido na Declaração Universal dos Direitos do Homem em 1948.

O que se percebe atualmente é a degradação e a omissão do Estado em relação à vida religiosa, à liberdade e ao patrimônio, atuando de forma omissiva, pois não há combate ao racismo mas mera tipificação penal que não se mostra eficaz, assim não há uma responsabilidade civil por parte do Estado. 
Assim, parte-se da premissa que as ciências humanas, direitos e políticas públicas se correlacionam entre si, por conseguinte, há necessidade de implementação de políticas públicas com o objetivo de concretizar o Direito, em especial a igualdade material religiosa, com fundamento na CRFB/88 que possui como objetivo a valoração dos princípios e normas.

Neste momento, há uma reprodução de todos os contextos da escravidão que antecedem o momento atual, ou seja, para o Estado é viável a manutenção hegemônica para manter o capitalismo e as desigualdades.

O Executivo e o Legislativo não demonstram interesse em proteger a religião africana e nem os negros, assim como foi no passado, quando após a libertação dos escravos, o Estado indenizou os donos de terras, em detrimento das pessoas escravizadas.

Percebe-se que o poder está concentrado em alguns atores governamentais, portanto não há que se falar em democracia, e sim em totalitarismo democrático.

\section{CONCLUSÃO}

Conclui-se o presente artigo, destacando a omissão dos atores governamentais, sejam eles Executivo, Legislativo e Judiciário, que, até o presente momento, não exercem a função constitucional de prover a igualdade substancial a toda população sob jurisdição do Brasil.

Contudo, este artigo não tem o condão de esgotar todas as formas de segregação que o povo negro continua sofrendo, o que será objeto de estudo em trabalhos futuros.

Desta forma, percebe-se, além da omissão estatal, a possibilidade de rompimento do Judiciário com o Legislativo e Executivo para que promovam políticas públicas para a proteção às religiões de matrizes africanas.

Uma vez que, querendo aplicar as normas de formas interdisciplinares no combate ao racismo, seja protegendo o corpo, a dignidade humana, a religião e o bem imaterial, o Poder Judiciário, no que se refere aos direitos fundamentais, tem o poder-dever de arbitrar valor econômico com o objetivo de reparação material, imaterial e também moral quanto ao patrimônio, e este terá um valor mensurável a partir do valor do bem para pessoa vítima de agressão.

Por fim, há de se destacar que toda violação praticada pelo eventual agressor é praticada a partir do dolo religioso, porém pratica, de forma 
concorrente, o dolo racial e possui culpa na deterioração do patrimônio - tanto o patrimônio imaterial como o patrimônio material - assim, conclui que a sentença proferida pelo Poder Judiciário poderá analisar em eventual caso concreto, tanto na esfera civil quanto na esfera penal, a reparação à violação ao crime de racismo, de religião e de patrimônio e a indenização pela violação ao bem material, imaterial e também indenização por danos morais, sendo certo que todas as indenizações são referentes ao ilícito praticado de forma diferente, pois os bens protegidos neste casos são distintos e interagem entre si.

Portanto, cada dano deverá ser suportado pelo violador dos direitos fundamentais de forma individualizada, para que assim seja proferida uma decisão justa, pois a indenização deverá sempre reparar toda a esfera da vítima de violência sofrida, que, no presente trabalho, será suportado pelo Estado, pois é nítido que há um fato gerador - a omissão - e também há uma omissão ou ação do agente publico. Neste contexto conclui-se que a responsabilidade estatal é extracontratual. Desta forma, os três atores governamentais são pessoas subordinadas ao Estado e, se causarem danos a terceiros, estará provocada a responsabilidade civil do Estado que, no presente trabalho, se caracteriza pela omissão legislativa em criar políticas públicas capazes de promover a igualdade entre as religiões, bem como pela omissão do Judiciário e do Executivo.

\section{REFERÊNCIAS}

ONU. "Declaração Universal dos Direitos Humanos". 217 (III) A. Paris, 1948. Disponível em: <http://www.un.org/en/universal-declaration-human-rights/> Acessado em: 9 nov. 2018

BRASIL. Decreto-lei 2.848, de 7 de dezembro de 1940. Código Penal. Disponível em: <http://www.planalto.gov.br/ccivil_03/Decreto-Lei/ Del2848.htm>. Acesso em: 26 nov. 2018.

BRASIL. Lei 10.460, de 10 de janeiro de 2002. Institui o Código Civil. Disponível em: <http://www.planalto.gov.br/ccivil_03/leis/2002/L10406compilada.htm>. Acesso em: 26 nov. 2018.

BRASIL. Constituição (1988). Constituição da República Federativa do Brasil de 1988. Disponível em: <http://www.planalto.gov.br/ccivil_03/ constituicao/constituicaocompilado.htm> Acesso em: 26 nov. 2018. 
FRESTON, Paul. Protestante e políticas no Brasil: da Constituinte ao $/ \mathrm{m}$ pechamentt. 1993. Tese (Doutorado em Ciências Sociais) - Instituto de Filosofia e Ciências Humanas, Universidade Estadual de Campinas, Campinas, 1993.

MORAES, Alexandre de. Direito constitucional. 14. ed. São Paulo: Atlas, 2003.

NASCIMENTO, Wanderson Flor do. Intolerância ou racismo. Hora Grande, [S.I.], ano 21, n. 167, 2016.

PARA LÍDERES religiosos, crimes de intolerância estão associados à discriminação racial. Governo do Brasil, [S.I.], 8 maio 2016. Intolerância religiosa. Disponível em: <http://www.brasil.gov.br/intolerancia-religiosa/ textos/para-lideres-crimes-de-intolerancia-religiosa-estao-associados-adiscriminacao-racial>. Acessado em: 6 nov. 2018.

PIERUCCI, A.F. Representantes de Deus em Brasília: a Bancada Evangélica na Constituinte. Ciências Sociais Hoje, São Paulo, p.p. 104-132, 1989.

QUINTÃO, Graziela Ferreira. A nova direita cristã: alianças, estratégias e transfiguração do discurso religioso em torno do projeto de cura gay. Estudo Social, [S.I.], v. 22, n. 42, p.p. 53-71, 2017.

WERNECK, Jurema. Racismo institucional e saúde da população negra. Saúde e Sociedade, São Paulo, v. 25, n. 3, p. 535-549, 2016. 